\title{
Bactericidal and Antiproliferative Effects of Peripheral Parenteral Nutrition Solutions with Sodium Bisulfite on Pathogenic Microorganisms in Catheter Lumens
}

\author{
Hiroshi Ohara ${ }^{1,2}$, Masanori Watanabe ${ }^{1}$, Masamu Takebayashi ${ }^{1}$, Saori Abe ${ }^{1}$, Tetsuya Matsuzaki ${ }^{1}$ and \\ Masataka Hayasaka ${ }^{1}$ \\ 1. Department of Clinical Pharmacy, School of Pharmaceutical Sciences, Ohu University, 31-1 Misumido, Tomitamachi-Aza, Koriyama, Fukushima 963-8611, \\ Japan. \\ 2. Department of Pharmacy, Ohu University Hospital, 31-1 Misumido, Tomitamachi-aza, Koriyama, Fukushima 963-8611, Japan. \\ $\triangle$ Corresponding author: Hiroshi Ohara, Ph.D. Department of Clinical Pharmacy, School of Pharmaceutical Sciences, Ohu University, 31-1 Misumido, \\ Tomitamachi-aza, Koriyama, Fukushima 963-8611, Japan; Tel./Fax: +81-24-932-9244; E-mail: h-ohara@pha.ohu-u.ac.jp. \\ (c) The author(s). This is an open access article distributed under the terms of the Creative Commons Attribution License (https://creativecommons.org/licenses/by/4.0/). \\ See http://ivyspring.com/terms for full terms and conditions.
}

Received: 2020.05.29; Accepted: 2020.06.26; Published: 2020.07.11

\begin{abstract}
Catheter-related bloodstream infections (CRBSIs) due to pathogenic microorganisms pose a major threat to patients requiring parenteral nutrition (PN). Additives contained in medicines and foods have antiproliferative and bacteriostatic effects on pathogenic microorganisms. Therefore, PN solutions containing additives may also have an antibacterial effect. However, so far, there have been no reports on or observations of a PN solution with bactericidal activity. In this study, we assessed several nutrition solutions with antimicrobial activities and investigated their effects on pathogenic microorganisms colonizing catheter lumens. We selected the highly acidic Plas-Amino ${ }^{\circledR}$ (PA), which contains a large amount of sodium bisulfite as a preservative and potentially has an antimicrobial effect. In this study, we used the following pathogenic bacteria as the main causatives of CRBSls: Staphylococcus aureus, Staphylococcus epidermidis, Bacillus cereus, Serratia marcescens, Pseudomonas aeruginosa, and Candida albicans. We then created a catheter lumen microorganism contamination model and evaluated the antibacterial effect of PA; we found that all bacteria in the control group grew significantly in the catheter lumen in a time-dependent manner at 48 and $72 \mathrm{~h}$. On the other hand, we demonstrated that PA has bactericidal effects on $S$. aureus, $S$. epidermidis, B. cereus, $S$. marcescens, and $P$. aeruginosa in the catheter lumen and confirmed that it has a remarkable antiproliferative effect on $C$. albicans. Hence, we concluded that highly acidic PN solutions that contain a preservative like sodium bisulfite have bactericidal and growth inhibition effects on microorganisms in the catheter lumens of patients with CRBSIs and patients with totally implantable central venous access devices, in whom it is difficult to remove the catheter.
\end{abstract}

Key words: parenteral nutrition; sodium bisulfite; bactericidal action; microbial growth inhibition; catheter-related bloodstream infection

\section{Introduction}

Catheter-related bloodstream infections (CRBSIs) due to pathogenic microorganisms are healthcare-associated infections that result in systemic complications and have a profound effect on patient prognosis [1-6]. Removal of the intravenous catheter is effective when a CRBSI occurs in a patient undergoing treatment with a nutrition solution [7]. However, repeated removal and catheterization of central venous catheters (CVCs) and totally implantable central venous access devices (CVADs) in elderly patients or patients who require long-term parenteral nutrition $(\mathrm{PN})$ therapy make it difficult to maintain access vessels to the central venous system and reduce the patient's quality of life. Ethanol lock therapy and antimicrobial lock therapy have been used to fight against CRBSIs in addition to catheter removal [8-13]. However, the evidence and scientific basis for ethanol lock therapy are currently 
insufficient $[7,14]$ and antimicrobial lock therapy is not recommended by the Centers for Disease Control and Prevention because it may cause the pathogenic microorganisms to acquire resistance [15]. On the other hand, it has been reported that taurolidine, a substance with antibacterial activity, is effective in preventing the occurrence of CRBSIs [16, 17]. The European Society for Clinical Nutrition and Metabolism guidelines on home parenteral nutrition recommend taurolidine lock solution as an additional strategy to prevent CRBSIs (Grade of Recommendation B) [18]. Additives or $\mathrm{pH}$ adjustments in pharmaceuticals or foods affect the survival of microbial pathogens. Ascorbic acid, which is widely used as a food additive and a drug, has a bactericidal effect due to the generation of reactive oxygen species resulting from the Fenton reaction [19, 20]. Citric acid is also added to pharmaceuticals and foods as a $\mathrm{pH}$ adjuster. However, citric acid has strong acidity and antibacterial activity due to the release of hydrogen ions, which inhibit the metabolism of microorganisms [21]. In addition, sodium bisulfite exerts a strong bactericidal action by inhibiting ATP synthesis and bacterial metabolism [22-24]. Sodium bisulfite is used as a stabilizing agent or antioxidant in commercially available PN solutions in Japan. Therefore, in a catheter lumen contaminated with a bacterial pathogen, it is possible to sterilize it by passing a highly acidic PN solution rich in a preservative. However, the bactericidal action and growth inhibition effect of PN solutions have not yet been examined. In this study, we focused on Plas-Amino ${ }^{\circledR}$ (PA) as a commercially available PN solution that contains the highest amount of sodium bisulfite as a preservative and the highest acidity in Japan [25], and investigated its effect on pathogenic microorganisms colonizing catheter lumen.

\section{Materials and Methods}

\section{Microorganisms employed}

Microbial pathogens were selected based on the data from a large-scale multicenter survey carried out by Wisplinghoff et al. [1] as well as the CRBSI report in Japan [26, 27]. Standard American Type Culture Collection (ATCC) strains for all the microorganisms were purchased from Microbiologics, Inc. (St. Cloud, MN, USA): Staphylococcus aureus (ATCC6538), Staphylococcus epidermidis (ATCC12228), Bacillus cereus (ATCC11778), Serratia marcescens (ATCC13880), Pseudomonas aeruginosa (ATCC9027), and Candida albicans (ATCC10231).

\section{Test solutions}

BFLUID $^{\circledR}$ (BF), a commercial peripheral parenteral nutrition (PPN) solution containing glucose, electrolytes, and amino acids, was purchased from Otsuka Pharmaceutical Factory, Inc. (Tokushima, Japan). Otsuka MV Injection ${ }^{\circledR}$ (MVs), a commercial multivitamin preparation containing both water-soluble vitamins (vitamins $B_{1}, B_{2}, B_{6}, B_{12}$, and $C$, folic acid, nicotinamide, biotin, and panthenol) and water-insoluble vitamins (vitamins A, D, E, and K), was purchased from Otsuka Pharmaceutical Factory, Inc. In addition, PA, also purchased from Otsuka Pharmaceutical Factory, Inc., was used as a nutrition solution formulation that possibly has an antimicrobial activity. PA is a highly acidic ( $\mathrm{pH} 4.6)$ solution that contains a higher concentration of sodium bisulfite $(0.5 \mathrm{~g} / \mathrm{L})$ as a preservative than that in the other nutrition solutions [25]. Tables 1 and 2 show the compositions of BF, PA, and MVs. In order to create a catheter lumen microorganism contamination model in this experiment, a test solution suitable for bacterial colonization and growth was prepared by adding $\mathrm{MVs}$ to $1,000 \mathrm{~mL}$ of $\mathrm{BF}$ (BF-MVs).

Table 1. Composition of BFLUID ${ }^{\circledR}(\mathrm{BF})$ and Plas-Amino ${ }^{\circledR}(\mathrm{PA})$

\begin{tabular}{|c|c|c|c|}
\hline Category & Component & BFLUID $^{\circledR}$ & Plas-Amino ${ }^{\circledR}$ \\
\hline \multicolumn{4}{|c|}{ Composition per $500 \mathrm{~mL}$} \\
\hline Carbohydrate & Glucose & $37.50 \mathrm{~g}$ & $37.50 \mathrm{~g}$ \\
\hline \multirow[t]{20}{*}{ Amino Acids } & L-Leucine & $2.100 \mathrm{~g}$ & $2.05 \mathrm{~g}$ \\
\hline & L-Isoleucine & $1.200 \mathrm{~g}$ & $0.90 \mathrm{~g}$ \\
\hline & L-Valine & $1.200 \mathrm{~g}$ & $1.00 \mathrm{~g}$ \\
\hline & $\begin{array}{l}\text { L-Lysine } \\
\text { Hydrochloride }\end{array}$ & $1.965 \mathrm{~g}$ & $3.10 \mathrm{~g}$ \\
\hline & (as L-Lysine) & $(1.573 \mathrm{~g})$ & $(2.48 \mathrm{~g})$ \\
\hline & L-Threonine & $0.855 \mathrm{~g}$ & $0.90 \mathrm{~g}$ \\
\hline & L-Tryptophan & $0.300 \mathrm{~g}$ & $0.29 \mathrm{~g}$ \\
\hline & L-Methionine & $0.585 \mathrm{~g}$ & $1.20 \mathrm{~g}$ \\
\hline & Acetylcysteine & $0.202 \mathrm{~g}$ & - \\
\hline & (as L-Cysteine) & $(0.150 \mathrm{~g})$ & - \\
\hline & L-Phenylalanine & $1.050 \mathrm{~g}$ & $1.45 \mathrm{~g}$ \\
\hline & L-Tyrosine & $0.075 \mathrm{~g}$ & - \\
\hline & L-Arginine & $1.575 \mathrm{~g}$ & $1.10 \mathrm{~g}$ \\
\hline & L-Histidine & $0.750 \mathrm{~g}$ & $0.50 \mathrm{~g}$ \\
\hline & L-Alanine & $1.200 \mathrm{~g}$ & - \\
\hline & L-Proline & $0.750 \mathrm{~g}$ & - \\
\hline & L-Serine & $0.450 \mathrm{~g}$ & - \\
\hline & Glycine & $0.855 \mathrm{~g}$ & $1.70 \mathrm{~g}$ \\
\hline & L-Aspartic Acid & $0.150 \mathrm{~g}$ & - \\
\hline & L-Glutamic Acid & $0.150 \mathrm{~g}$ & - \\
\hline \multirow[t]{11}{*}{ Electrolytes } & $\mathrm{Na}^{+}$ & $17.5 \mathrm{mEq}$ & $17 \mathrm{mEq}$ \\
\hline & $\mathrm{K}^{+}$ & $10 \mathrm{mEq}$ & - \\
\hline & $\mathrm{Mg}^{2+}$ & $2.5 \mathrm{mEq}$ & - \\
\hline & $\mathrm{Ca}^{2+}$ & $2.5 \mathrm{mEq}$ & - \\
\hline & $\mathrm{Cl}^{-}$ & $17.5 \mathrm{mEq}$ & $17 \mathrm{mEq}$ \\
\hline & $\mathrm{SO}_{4}{ }^{2-}$ & $2.5 \mathrm{mEq}$ & - \\
\hline & Acetate- & $8 \mathrm{mEq}$ & - \\
\hline & L-Lactate- & $10 \mathrm{mEq}$ & - \\
\hline & Citrate $^{3-}$ & $3 \mathrm{mEq}$ & - \\
\hline & $\mathrm{P}$ & $5 \mathrm{mmol}$ & - \\
\hline & $\mathrm{Zn}$ & $2.5 \mu \mathrm{mol}$ & - \\
\hline Vitamin & $\begin{array}{l}\text { Thiamine } \\
\text { Chloride } \\
\text { Hydrochloride }\end{array}$ & $0.96 \mathrm{mg}$ & - \\
\hline $\mathrm{pH}$ & & Approximately 6.7 & Approximately 4.6 \\
\hline ORP & & Approximately 3 & Approximately 3 \\
\hline Additive Agent & Sodium Bisulfite & $0.05 \mathrm{~g} / \mathrm{L}$ & $0.5 \mathrm{~g} / \mathrm{L}$ \\
\hline
\end{tabular}




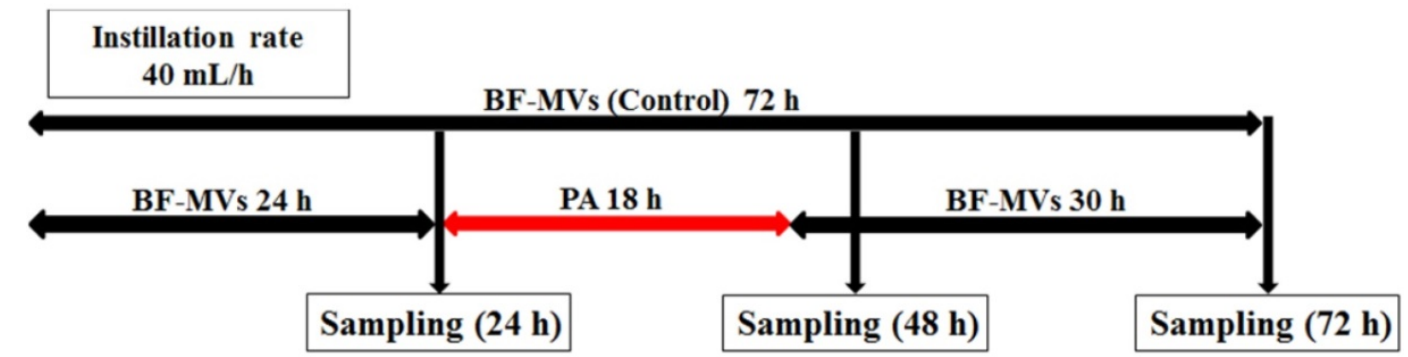

Figure 1. Experimental procedure, first experiment for all bacterial pathogens. In the control group, BFLUID ${ }^{\circledR}$ (BF) with Otsuka MV Injection ${ }^{\circledR}$ (MVs, BF-MVs) was added dropwise for $72 \mathrm{~h}$. In the test group, BF-MVs was added dropwise for $24 \mathrm{~h}$, and then Plas-Amino ${ }^{\circledR}(\mathrm{PA})$ was added dropwise for $18 \mathrm{~h}$, followed by the addition of BF-MVs dropwise again for $30 \mathrm{~h}$. Then, after 24,48 , and $72 \mathrm{~h}$, all aliquot samples were collected and the colony-forming unit (CFU)/mL value was measured.

Table 2. Composition of MVs (Otsuka MV Injection ${ }^{\circledR}$ )

\begin{tabular}{ll}
\hline Composition per $4 \mathrm{~mL}$ & \\
\hline Water-Soluble Vitamins & $3.1 \mathrm{mg}$ \\
Vitamin $B_{1}$ & $3.6 \mathrm{mg}$ \\
Vitamin $B_{2}$ & $4.0 \mathrm{mg}$ \\
Vitamin $_{6}$ & $0.005 \mathrm{mg}$ \\
Vitamin $B_{12}$ & $100 \mathrm{mg}$ \\
Vitamin C & $0.4 \mathrm{mg}$ \\
Folic Acid & $40 \mathrm{mg}$ \\
Nicotinamide & $0.06 \mathrm{mg}$ \\
Biotin & $14 \mathrm{mg}$ \\
Panthenol & \\
Fat-Soluble Vitamins & $3300 \mathrm{Vit} . A \mathrm{IU}$ \\
Vitamin A Oil & $0.005 \mathrm{mg}$ \\
Vitamin $\mathrm{D}_{3}$ & $10 \mathrm{mg}$ \\
Vitamin E & $2 \mathrm{mg}$ \\
Vitamin K &
\end{tabular}

Vit.A IU, international unit for vitamin A.

\section{Preparation of the catheter lumen microorganism contamination model, incubation, and sampling}

One platinum loop from each strain was suspended and diluted in a physiological saline (Otsuka Pharmaceutical Factory, Inc.) to obtain a constant concentration of each pathogenic microorganism solution. Then, $5 \mathrm{~mL}$ of each solution was injected into a PLANECTA Infusion Set ${ }^{\circledR}$ (JMS, Inc., Tokyo, Japan) and a TOP Extension Tube ${ }^{\circledR}$ (TOP, Inc., Tokyo, Japan) connected to BF-MVs, and solution flow was blocked for $1 \mathrm{~h}$. BF-MVs was added dropwise at a constant rate of $40 \mathrm{~mL} / \mathrm{h}$ to remove any microorganisms that did not colonize the catheter lumen.

Droplet samples (10-20 mL) were collected at 24 $\mathrm{h}$ after the addition of each bacterial pathogen. After sampling, we continued adding BF-MVs dropwise in the control group and replaced BF-MVs with PA in the test group for $18 \mathrm{~h}(40 \mathrm{~mL} / \mathrm{h})$. We selected $18 \mathrm{~h}$ because our preliminary examination showed that sterilization requires more than $12 \mathrm{~h}$ in vitro (Table $1 \mathrm{~S}$ ). Thereafter, PA was replaced with BF-MVs and added again dropwise. One aliquot $(10-20 \mathrm{~mL})$ of each test solution was sampled at 48 and $72 \mathrm{~h}$. All experiments were performed three times at $25^{\circ} \mathrm{C}$. Figure 1 shows a schematic diagram of the experimental procedure.

\section{Measurement of microbial colony}

All sampled test solutions were assessed using the membrane filter method in the presence of a small number of microorganisms. All aliquots (10-20 mL) were filtered using a $0.45 \mu \mathrm{m}$ nitrocellulose membrane filter (ADVANTEC Co., Ltd., Tokyo, Japan) to perform a sterility test as described by the Japanese Pharmacopoeia [28], and then each filter was placed on a soybean-casein digest (SCD) agar medium. When necessary, any test solution sampled was serially diluted with a physiological saline before inoculation. The number of microbial pathogen colony-forming units (CFUs) on each SCD agar medium was counted after $24 \mathrm{~h}$ of incubation at $37^{\circ} \mathrm{C}$, and the value of $\mathrm{CFUs} / \mathrm{mL}$ was calculated using the number of CFUs per SCD agar medium, the inoculum dose, and the dilution ratio. Results are represented as CFUs/mL values in semilogarithmic graphs. It has previously been shown that the biological significance of bacterial growth can be evaluated without performing any statistical analyses; hence, no statistical analyses were performed for the obtained data [29-32].

\section{Results}

In the control group (with only BF-MVs), the standard strain of S. aureus (ATCC6538) colonized and grew in the catheter lumen treated with BF-MVs at 24 $\mathrm{h}$ and rapidly increased at 48 and $72 \mathrm{~h}$. In addition, $S$. aureus proliferated from $9.3 \times 10^{2} \mathrm{CFUs} / \mathrm{mL}$ to $9.7 \times$ $10^{5} \mathrm{CFUs} / \mathrm{mL}$ after $48 \mathrm{~h}$ and reached $3.1 \times 10^{7}$ $\mathrm{CFUs} / \mathrm{mL}$ after $72 \mathrm{~h}$ (Figure 2A). The standard strain of B. cereus (ATCC11778) significantly colonized and grew in the catheter lumen treated with BF-MVs at 24 $\mathrm{h}$ and rapidly increased at 48 and $72 \mathrm{~h}$. Moreover, $B$. cereus proliferated from $7.1 \times 10^{5} \mathrm{CFUs} / \mathrm{mL}$ to $2.0 \times$ $10^{7} \mathrm{CFUs} / \mathrm{mL}$ after $48 \mathrm{~h}$ and reached $3.3 \times 10^{9}$ $\mathrm{CFUs} / \mathrm{mL}$ after $72 \mathrm{~h}$ (Figure 2C). However, the standard strain of S. epidermidis (ATCC12228) hardly colonized and grew in the catheter lumen treated with BF-MVs at $24 \mathrm{~h}$ and increased slowly at 48 and $72 \mathrm{~h}$. Moreover, S. epidermidis proliferated from $2.0 \times 10^{0}$ CFUs/mL to $1.8 \times 10^{1} \mathrm{CFUs} / \mathrm{mL}$ after $48 \mathrm{~h}$ and to 1.4 
$\times 10^{3} \mathrm{CFUs} / \mathrm{mL}$ after $72 \mathrm{~h}$ (Figure 2B). The standard strain of $S$. marcescens (ATCC13880) slightly colonized and grew in the catheter lumen treated with BF-MVs at $24 \mathrm{~h}$ and increased significantly at 48 and $72 \mathrm{~h}$. In addition, S. marcescens proliferated from $1.7 \times 10^{1}$ CFUs $/ \mathrm{mL}$ to $4.4 \times 10^{4} \mathrm{CFUs} / \mathrm{mL}$ after $48 \mathrm{~h}$ and to 1.7 $\times 10^{6} \mathrm{CFUs} / \mathrm{mL}$ after $72 \mathrm{~h}$ (Figure 2D). The standard strain of $P$. aeruginosa (ATCC9027) also slightly colonized and grew in the catheter lumen treated with BF-MVs at $24 \mathrm{~h}$ and increased slowly at 48 and $72 \mathrm{~h}$. In addition, $P$. aeruginosa proliferated from $4.3 \times 10^{1}$ CFUs/mL to $1.0 \times 10^{3} \mathrm{CFUs} / \mathrm{mL}$ after $48 \mathrm{~h}$ and to 9.4 $\times 10^{3} \mathrm{CFUs} / \mathrm{mL}$ after $72 \mathrm{~h}$ (Figure 2E). On the other hand, no pathogenic microbes were detected after 48 and $72 \mathrm{~h}$ in the PA group, and it was concluded that PA has a bactericidal effect on all the pathogenic bacteria used (Figs. 2A-2E). Furthermore, the standard strain of C. albicans (ATCC10231) colonized and grew in the catheter lumen treated with BF-MVs at $24 \mathrm{~h}$ and rapidly increased at 48 and $72 \mathrm{~h}$. In addition, C. albicans proliferated from $1.7 \times 10^{2}$ CFUs/mL to $3.2 \times 10^{3}$ CFUs/mL after $48 \mathrm{~h}$ and to 1.1 $\times 10^{6} \mathrm{CFUs} / \mathrm{mL}$ after $72 \mathrm{~h}$ (Figure $2 \mathrm{~F}$ ). Although no bactericidal effect was observed on the C. albicans fungus in the PA group, the addition of PA dropwise had a significant growth inhibition effect on C. albicans in comparison with the control group. The growth of C. albicans was inhibited from $2.0 \times 10^{2} \mathrm{CFUs} / \mathrm{mL}$ to $1.3 \times 10^{3} \mathrm{CFUs} / \mathrm{mL}$ after $48 \mathrm{~h}$ and to $3.7 \times 10^{3}$ CFUs/mL after $72 \mathrm{~h}$ (Figure $2 \mathrm{~F}$ ).

We next performed additional experiments on $C$. albicans. A schematic diagram of the experimental procedure is shown in Figure 1S. In the first $24 \mathrm{~h}$, the standard strain of C. albicans (ATCC10231) colonized and grew in the catheter lumen in a similar way to BF-MVs. Although no bactericidal action was observed, the intermittent administration of PA exerted a potent antiproliferative effect against $C$. albicans. The growth of $C$. albicans was inhibited from $9.0 \times 10^{1} \mathrm{CFUs} / \mathrm{mL}$ to $1.8 \times 10^{1} \mathrm{CFUs} / \mathrm{mL}$ after $48 \mathrm{~h}$ and to $2.3 \times 10^{2} \mathrm{CFUs} / \mathrm{mL}$ after $72 \mathrm{~h}$ (Figure $2 \mathrm{~S}$ ).

\section{Discussion}

Nutrients required for growth differ depending on the bacterial species, and there have been reports on the growth characteristics of bacteria in commercially available PPN and total parenteral nutrition (TPN) solutions [33-36]. We have previously demonstrated that $C$. albicans do not grow in commercial PPN solutions but rather grow significantly in PPN solutions with biotin [37]. However, much is still unknown about the relationship between bacterial growth and nutritional factors. Moreover, $\mathrm{pH}$ and osmotic pressure, in addition to nutrients, are important factors in the growth of bacteria. It has been shown that using a PPN solution with a high $\mathrm{pH}$ value and low osmolarity is more suitable for microbial growth than using a TPN solution with a low $\mathrm{pH}$ value and high osmolarity [38]. Commercially available PN solutions contain various nutrients, making them suitable media for bacterial growth $[2,35]$.

We herein attempted to create a catheter lumen microorganism contamination model using typical CRBSI-causing pathogens. We added multivitamins to commercially available PPN solutions and prepared solutions (BF-MVs) more suitable for bacterial growth. When all pathogenic microorganism solutions were injected into the catheter and the flow pass was blocked for $1 \mathrm{~h}$, all bacteria showed colonization and growth in the catheter lumen (Figure 2). Thus, we established a method for constructing a catheter lumen microorganism contamination model. In particular, B. cereus was found to colonize and proliferate significantly in the catheter lumen (Figure 2C) and to float in the air or adhere to the fingers while handling linen [26, 39]. After handling linen, treatment with nutrition solutions should be avoided. Moreover, S. aureus were found to exhibit remarkable colonization and proliferation in the catheter lumen similar to those of B. cereus (Figure 2A). Shiraishi et al. reported that $S$. aureus grow in TPN solutions containing lipid emulsions [33]. In addition, it has been reported that $S$. aureus require nicotinamide [36]. It was also found that $S$. epidermidis and $P$. aeruginosa hardly colonize in the catheter lumen and grow slowly after 48 and $72 \mathrm{~h}$ (Figs. 2B and 2E). Generally, $P$. aeruginosa are resistant to a wide range of antibiotics and often cause opportunistic infections. In addition, S. epidermidis are considered to be the most frequently identified Gram-positive cocci and are a causative agent of CRBSIs [1]. Therefore, unlike what we expected, we considered the colonization and proliferation of S. epidermidis in the catheter lumen to be the highest (Figure 2B), a result that is in fact very interesting. S. epidermidis are considered to be indigenous bacteria of the epidermis, which can enter the blood vessels during an injection and cause a BSI while using blood as a source of nutrition. It was also found that $S$. marcescens slightly colonize and proliferate in the catheter lumen and increase significantly at 48 and $72 \mathrm{~h}$ (Figure 2D). Omotani et al. reported that $S$. marcescens grow well in PPN solutions, which are less nutritious than TPN solutions [36]. In addition, it was found that C. albicans proliferates rapidly 48 and $72 \mathrm{~h}$ after colonization in the catheter lumen (Figure 2F). Generally, CRBSIs caused by $C$. albicans are known to have a high mortality rate, and attention must be paid to the loss of vision that might probably occur because of fungal endophthalmitis $[5,40]$. CRBSIs are mainly caused by 
bacterial pathogens adhering to the catheter connection, outer circumference, and lumen during solution preparation, catheter insertion, and solution exchange [41]. Our data indicate that pathogenic microorganisms can use nutrition solutions to grow
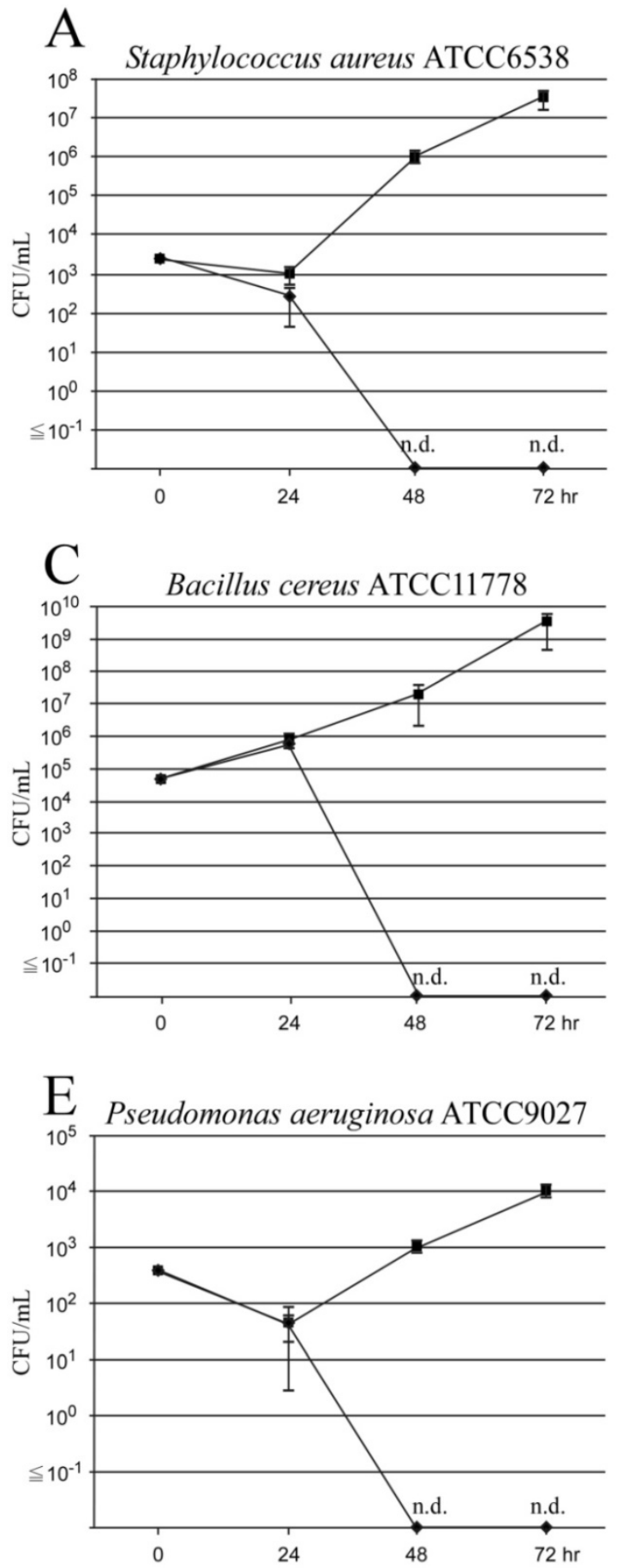

when they colonize a catheter lumen. Therefore, a catheter lumen microorganism contamination model may be a useful tool to elucidate the mechanisms of CRBSIs and study how to prevent pathogenic bacterial contamination.
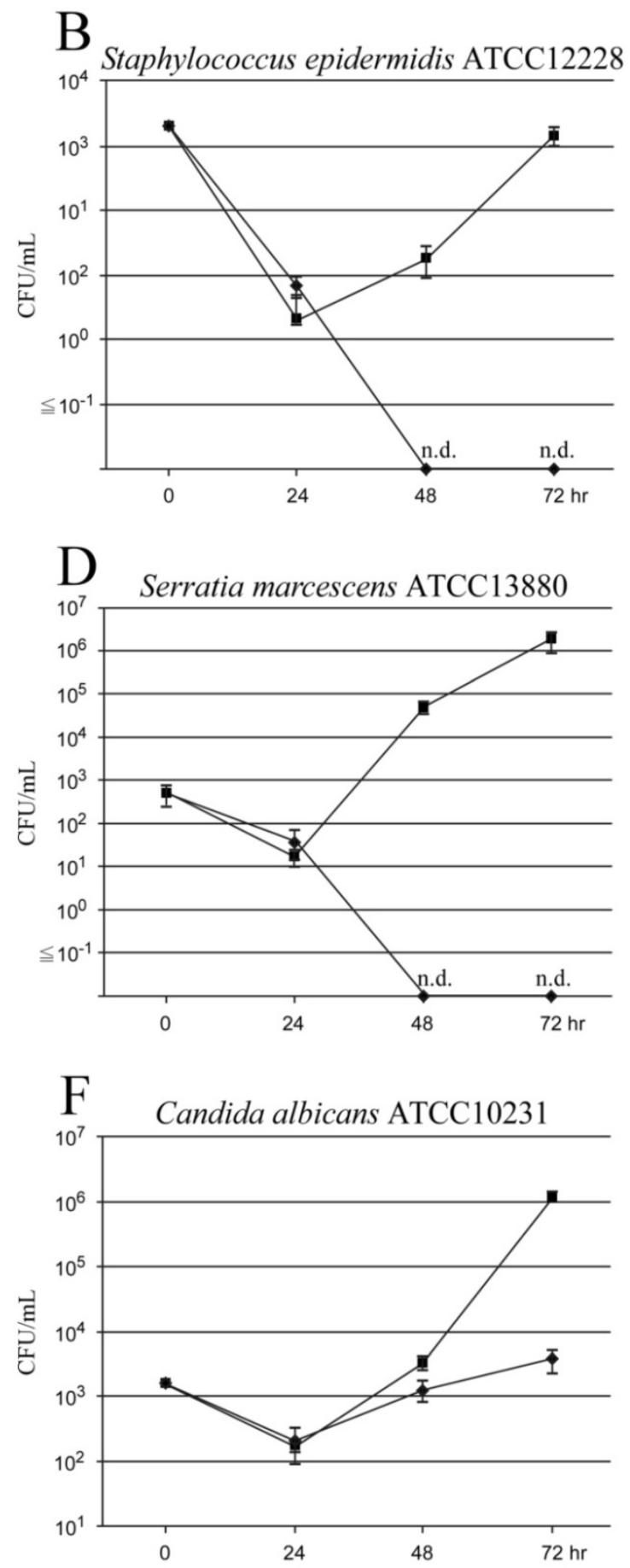

Figure 2. Bactericidal and antiproliferative effects of Plas-Amino ${ }^{\circledR}$ (PA) on pathogenic microorganisms. Droplet samples were collected at 24 , 48 , and 72 h, and the colony-forming unit (CFU)/mL value was measured. (A) Bactericidal effect of PA on Staphylococcus aureus. (B) Bactericidal effect of PA on Staphylococcus epidermidis. (C) Bactericidal effect of PA on Bacillus cereus. (D) Bactericidal effect of PA on Serratia marcescens. (E) Bactericidal effect of PA on Pseudomonas aeruginosa. (F) Antiproliferative effect of PA on Candida albicans. PA $(\diamond)$ and BFLUID ${ }^{\circledR}(B F)$ with multivitamins (BF-MVs; $\bullet$ ) were used as the control. All data are represented as the mean \pm standard deviation (SD; n=3). n.d.: not detectable. 
In this study, we investigated the effects of PA on pathogenic bacteria colonizing catheter lumens to prevent the occurrence of CRBSIs. After flowing PA into the catheter lumen contaminated with each bacterium for $18 \mathrm{~h}$, PA was switched to BF-MVs and aliquots were collected 48 and $72 \mathrm{~h}$ later. None of the microorganisms was detected in the samples. Therefore, we concluded that PA has a bactericidal effect on $S$. aureus, $S$. epidermidis, B. cereus, $S$. marcescens, and $P$. aeruginosa (Figs. 2A-2E), and we confirmed that it has an antiproliferative effect on $C$. albicans (Figure 2F). In addition to chitin, C. albicans have a strong cell wall consisting of $\beta$-D-glucan, which promotes their survival and growth under hyperosmotic and acidic conditions, such as TPN solutions, in comparison to CRBSI-causing bacteria [34, 37]. Hence, it was suggested that the penetration of sodium bisulfite contained in PA into the cells was partially blocked and that no bactericidal effect could be obtained. Among all the commercially available PPN solutions in Japan, PA is known to contain the highest concentration of sodium bisulfite $(0.5 \mathrm{~g} / \mathrm{L})$ as a preservative [25]. Sodium bisulfite $\left(\mathrm{NaHSO}_{3}\right)$, which mainly exists in the form of sulfurous acid $\left(\mathrm{SO}_{2}\right.$ or $\left.\mathrm{H}_{2} \mathrm{SO}_{3}\right)$ in its molecular form with a low $\mathrm{pH}[23,42,43]$, is a widely used preservative in pharmaceuticals and foods, which has antioxidative and antibacterial effects. This molecular form has the ability to permeate the cells and inhibit the ATP synthesis and metabolism of bacteria [22-24]. Therefore, we considered PA to be highly acidic, to exhibit an increased abundance of molecular forms, and to have bactericidal and antiproliferative effects on pathogenic microorganisms. We also revealed that PA has bactericidal and antiproliferative effects on pathogenic microorganisms in catheter lumens. The limitations of this experimental model are that the treatment duration of PA was $18 \mathrm{~h}$ in all experiments and that we did not observe the growth trend of $C$. albicans after $72 \mathrm{~h}$. Although PA is an infusion formulation that does not contain vitamins, it suffices as an energy source for the growth and development of bacterial pathogens because it mainly consists of glucose, amino acids and electrolytes. Hence, if no bacterial pathogens are detected after PA treatment, it can be concluded that the bactericidal effect observed is due to the low $\mathrm{pH}$ of and/or sodium bisulfite contained in PA. In this study, we found that PA remarkably suppressed the growth of $C$. albicans and demonstrated a clear bactericidal effect against bacterial pathogens other than fungi. Intermittent administration of PA against $C$. albicans may have a certain effect on the prevention of CRBSIs in cases where removing the CVC from the patient is difficult. Although catheter removal is effective in CRBSI, repeated removal and insertion can result in the loss of the catheter insertion path as a result of obstruction of the access vessel. Furthermore, implantation of totally implantable CVADs carries the risk of serious mechanical complications, such as air embolisms, arterial puncture, and pneumothorax. Intermittent administration of PA might be effective in preventing CRBSIs in cases where catheter removal from the patients is difficult. In the future, it is expected that solutions with an antimicrobial effect, such as PA, will help control CRBSIs, and we also hope that our research results prove helpful in the suppression of CRBSIs.

\section{Conclusion}

This study shows that highly acidic parenteral nutrition (PN) solutions containing a high concentration of sodium bisulfite have bactericidal and antiproliferative effects. It was also found that Plas-Amino $^{\circledR}$ (PA) can be used as a peripheral parenteral nutrition (PPN) solution, which has a low risk of allergic reactions and side effects in patients. If a central venous catheter (CVC) or totally implantable CVAD becomes contaminated, it is possible to use PA to sterilize the catheter lumen and suppress bacterial growth without removing the catheter or the device. Component analysis of solutions that have secondary effects, such as PA, can help develop new lock therapy alternatives to ethanol lock therapy and antimicrobial lock therapy.

\section{Supplementary Material}

Supplementary figures and table. http://www.medsci.org/v17p1833s1.pdf

\section{Competing Interests}

The authors have declared that no competing interest exists.

\section{References}

1. Wisplinghoff $H$, Bischoff $T$, Tallent $S M$, et al. Nosocomial bloodstream infections in US hospitals analysis of 24,179 cases from a prospective nationwide surveillance study. Clin Infect Dis. 2004; 39: 309-317.

2. Llop J, Badia MB, Comas D, et al. Colonization and bacteremia risk factors in parenteral nutrition catheterization. Clin Nutr. 2001; 20: 527-534.

3. Pronovost $\mathrm{P}$ Needham $\mathrm{D}$, Berenholtz $\mathrm{S}$, et al. An intervention to decrease catheter-related bloodstream infections in the ICU. N Engl J Med. 2006; 355: 2725-2732.

4. Banton J. Techniques to prevent central venous catheter infection: products, research, and recommendations. Nutr Clin Pract. 2006: 21: 56-61.

5. Tumbarello M, Posteraro B, Trecarichi EM, et al. Biofilm production by Candida species and inadequate antifungal therapy as predictors of mortality for patients with candidemia. J Clin Microbiol. 2007; 45: 1843-1850.

6. Daniels KR, Frei CR. The United States' progress toward eliminating catheter-related bloodstream infections: incidence, mortality, and hospital length of stay from 1996 to 2008. Am J Infect Control. 2013; 41: 118-121.

7. Mermel LA, Allon M, Bouza E, et al. Clinical practice guidelines for the diagnosis and management of intravascular catheter-related infection: 2009 update by the infectious diseases society of America. Clin Infect Dis. 2009; 49: $1-45$.

8. Metcalf SC, Chambers ST, Pithie AD. Use of ethanol locks to prevent recurrent central line sepsis. J Infect. 2004; 49: 20-22.

9. Chambers ST, Peddie B, Pithie A. Ethanol disinfection of plastic-adherent micro-organisms. J Hosp Infect. 2006; 63: 193-196. 
10. Segarra-Newnham M, Martin-Cooper EM. Antibiotic lock technique: a review of the literature. Ann Pharmacother. 2005; 39: 311-318.

11. Fortún J, Grill F, Martín-Dávila P, et al. Treatment of long-term intravascular catheter-related bacteraemia with antibiotic-lock therapy. J Antimicrob Chemother. 2006; 58: 816-821.

12. Fernandez-Hidalgo N, Almirante B, Calleja R, et al. Antibiotic-lock therapy for long-term intravascular catheter-related bacteraemia: results of an open, non-comparative study. J Antimicrob Chemother. 2006; 57: 1172-1180.

13. Snaterse M, Rüger W, Scholte Op Reimer WJ, et al. Antibiotic-based catheter lock solutions for prevention of catheter-related bloodstream infection: a systematic review of randomised controlled trials. J Hosp Infect. 2010; 75: 111.

14. Wolf J, Connell TG, Allison KJ, et al. Treatment and secondary prophylaxis with ethanol lock therapy for central line-associated bloodstream infection in paediatric cancer: a randomised, double-blind, controlled trial. Lancet Infect Dis. $2018 ; 18$ : 854-863.

15. O'Grady NP, Alexander M, Dellinger EP, et al. Guidelines for the prevention of intravascular catheter-related infections. Centers for disease control and prevention. MMWR Recomm Rep. 2002; 51: 1-29.

16. Tribler S, Brandt $\mathrm{CF}$, Petersen $\mathrm{AH}$, et al. Taurolidine-citrate-heparin lock reduces catheter-related bloodstream infections in intestinal failure patients dependent on home parenteral support: a randomized, placebo-controlled trial. Am J Clin Nutr. 2017; 106: 839-848

17. Wouters $\mathrm{Y}$, Theilla $\mathrm{M}$, Singer $\mathrm{P}$, et al. Randomised clinical trial: $2 \%$ taurolidine versus $0.9 \%$ saline locking in patients on home parenteral nutrition. Aliment Pharmacol Ther. 2018; 48: 410-422.

18. Loris P, Kurt B, Federico B, et al. ESPEN guideline on home parenteral nutrition. Clin Nutr. 2020; 39: 1645-1666.

19. Burkitt MJ, Gilbert BC. Model studies of the iron-catalysed Haber-Weiss cycle and the ascorbate-driven Fenton reaction. Free Radic Res Commun. 1990; 10: 265-280.

20. Catherine $\mathrm{V}$, Travis $\mathrm{H}$, Brian $\mathrm{W}$, et al. Mycobacterium tuberculosis is extraordinarily sensitive to killing by a vitamin C-induced Fenton reaction. Nat commu. 2013; 4: 1881-1906.

21. Arias-Moliz MT, Ferrer-Luque CM, Espigares-Rodríguez E, et al. Bactericidal activity of phosphoric acid, citric acid, and EDTA solutions against Enterococcus faecalis. Oral Surg Oral Med Oral Pathol Oral Radiol Endod. 2008; 106: e84-e89.

22. Freese E, Sheu CW, Galliers E. Function of lipophilic acids as antimicrobial food additives. Nature. 1973; 241: 321-325.

23. Murano A, Morinaga $\mathrm{N}$, Iwamaru $\mathrm{Y}$, et al. Acidic conditions enhance bactericidal effects of sodium bisulfite on Helicobacter pylori. Helicobacter. 2005; 10: 132-135.

24. Schobert B. The effects of sulfite or nitrite on turnover-dependent inhibition in the ATPase from Halobacterium saccharovorum are related to the binding of the second metal ion. Biochemistry. 1993; 32: 13204-13211.

25. [Internet] PMDA. The medical package insert, Plas-Amino ${ }^{\circledR}$ injection, Ninth edition. Otsuka Pharmaceutical Factory, Inc., Japan, 2020. https://www.info.pmda.go.jp/go/pack/3259510A3036_1_07/?view=frame\& style=SGML\&lang=ja

26. Sasahara T, Hayashi S, Morisawa Y, et al. Bacillus cereus bacteremia outbreak due to contaminated hospital linens. Eur J Clin Microbiol Infect Dis. 2011; 30: 219-226.

27. Iwaya A, Nakagawa S, Taneike I, et al. Serratia infection and sanitary management of fluid administration. Niigata-igakukai-zasshi. 2003; 117: 469478.

28. [Internet] The Japanese pharmacopoeia seventeenth edition. Japan: Ministry of Health, Labour and Welfare; 2016. https://www.mhlw.go.jp/stf/ seisakunitsuite/bunya/0000066597.html

29. Keammerer D, Mayhall CG, Hall GO, et al. Microbial growth patterns in intravenous fat emulsions. Am J Hosp Pharm. 1983; 40: 1650-1653.

30. Jarvis WR, Highsmith AK. Bacterial growth and endotoxin production in lipid emulsion. J Clin Microbiol. 1984; 19: 17-20.

31. Didier ME, Fischer S, Maki DG. Total nutrient admixtures appear safer than lipid emulsion alone as regards microbial contamination: growth properties of microbial pathogens at room temperature. JPEN J Parenter Enteral Nutr. 1998; 22: 291-296

32. Obayashi A, Oie S, Kamiya A. Microbial viability in preparations packaged for single use. Biol Pharm Bull. 2003; 26: 667-670.

33. Shiraishi T, Nakagawa Y. Evaluation of infusion fluids on outgrowth of several bacteria strains related to hospital-acquired infection. Jpn J Environ Infect. 2007; 22: 165-169.

34. Kuwahara T, Kaneda S, Shimono K, et al. Growth of microorganisms in total parenteral nutrition solutions without lipid. Int J Med Sci. 2010; 7: 43-47.

35. Kuwahara T, Kaneda S, Shimono $K$, et al. Effects of lipid emulsion and multivitamins on the growth of microorganisms in peripheral parenteral nutrition solutions. Int J Med Sci. 2013; 10: 1079-1084.

36. Omotani S, Tani K, Nagai K, et al. Water soluble vitamins enhance the growth of microorganisms in peripheral parenteral nutrition solutions. Int J Med Sci. 2017; $14:$ 1213-1219.

37. Ohara H, Matsuzaki T, Hayasaka M. Growth of Candida albicans in peripheral parenteral nutrition solutions supplemented with biotin. Jpn J Environ Infect. 2017; 32: 29-33.

38. Kuwahara T, Shimono K, Kaneda S, et al. Growth of microorganisms in total parenteral nutrition solutions containing lipid. Int J Med Sci. 2010; 7: 101-109.
39. Dohmae $\mathrm{S}$, Okubo $\mathrm{T}$, Higuchi $\mathrm{W}$, et al. Bacillus cereus nosocomial infection from reused towels in Japan. J Hosp Infect. 2008; 69: 361-367.

40. Durand ML. Endophthalmitis. Clin Microbiol Infect. 2013; 19: 227-234.

41. Mueller-Premru M, Gubina M, Kaufmann ME, et al. Use of semi-quantitative and quantitative culture methods and typing for studying the epidemiology of central venous catheter-related infections in neonates on parenteral nutrition. J Med Microbiol 1999; 48: 451-460.

42. Grant IF, Bancroft $\mathrm{K}$, Alexander M. Effect of $\mathrm{SO} 2$ and bisulfite on heterotrophic activity in an acid soil. Appl Environ Microbiol. 1979; 38: 78-83.

43. Fine JM, Gordon T, Sheppard D. The roles of $\mathrm{pH}$ and ionic species in sulfur dioxide- and sulfite-induced bronchoconstriction. Am Rev Respir Dis. 1987; 136: $1122-1126$. 